\title{
A SOCIOLOGIA DA INFÂNCIA COMO SUPORTE PARA OS PROFESSORES: A CRIANÇA E A ESSÊNCIA DO BRINCAR
}

Nathalia Franco Alves, Monique Bahr Pimentel, Márcia Regina Canhoto de Lima, José Milton de Lima

Universidade Estadual Paulista - UNESP, Educação Física, Presidente Prudente, SP. E-mail: nathalia fa@hotmail.com. Agência financiadora Pibic/Cnpq.

\section{RESUMO}

O presente artigo trata-se de um recorte de uma pesquisa de iniciação científica intitulada "A Ludicidade como eixo estruturador das culturas da infância, dando voz a criança", desenvolvida pelo grupo de pesquisa CEPELIJ- Centro de estudo e pesquisa em educação, ludicidade, infância e juventude, coordenado pelos professores doutores José Milton de Lima e Márcia Regina Canhoto de Lima, em parceria com uma escola de Educação Infantil de Presidente Prudente. Trata-se de uma pesquisa qualitativa do tipo - etnográfica que tem como aporte teórico a Sociologia da Infância. Tem por objetivos compreender como a Ludicidade é trabalhada dentro do contexto escolar, qual a postura das professoras diante desse eixo e permitir que a criança protagonize suas vivências. As observações são realizadas semanalmente, assim como os encontros dos bolsistas para a discussão do material teórico. Ocorrem também quinzenalmente uma reunião com um grupo maior denominado, Cultura Corporal, Saberes e Fazeres, que atualmente está estudando as diferentes vertentes sociológicas e uma disciplina de história que aborda todo o processo de desenvolvimento do ser humano e as diferentes sociedades. Como resultados, observou-se o envolvimento gradativo das professoras em relação à brincadeira, a transformação que ambas estão tendo desde que a pesquisa passou a contemplálas. Em relação às crianças, notou-se que em todas as situações elas estiverem como atores sociais e protagonistas.

Palavras Chave: Professoras, Infância, Escola.

THE SOCIOLOGY OF CHILDHOOD AS INSPIRATION FOR TEACHERS: THE CHILD AND THE ESSENCE OF THE PLAY

\begin{abstract}
This article this is a clipping of a scientific initiation research titled "Playfulness as structuring axis of cultures from childhood, giving voice to child", developed by the research group CEPELIJ-Centre for study and research in education, playfulness, childhood and youth, coordinated by professors doctors José Milton of Lima and Marcia Regina Left-handed de Lima, in partnership with a school of early childhood education of Presidente Prudente. It is a qualitative research of the type-theoretic contribution as ethnographic sociology of childhood. Aims to understand how playfulness is crafted within the school context, what the attitude of the teachers on this shaft and allow the child their good experiences. Commentsare performed weekly, as well as the meetings of the scholars for discussion of theoretical material. Also occur biweekly meeting with a larger group named, Body Culture, knowledge and practices, who is currently studying the different sociological aspects and a history course that covers the entire process of human development and the different societies. As a result, the gradual involvement of the teachers about the prank, the transformation that both are having since the search began to contemplate them. In relation to children, it was noted that in all situations they are as social actors and protagonists.
\end{abstract}

Key Words: Teachers, Childhood, School. 


\section{INTRODUÇÃO}

A infância, segundo Sarmento (2005), Aries (1981), Cordeiro (2008), Corsaro (2009) entre outros, trata-se de uma construção histórica. Por mais críticas que a obra do historiador Philipe Áries receba, as suas contribuições não podem ser negligenciadas. $O$ autor denota que as crianças antecedentes ao século XVII, eram concebidas como adultos em miniatura, pequenos seres que reproduziam todas as ações dos adultos próximos a eles.

Pinto e Sarmento (1997) reafirmam essas considerações quando denotam que as crianças existiram desde sempre, mas a infância como categorial social só teve início no final do século XVI e início do século XVII. Ao ser relatado a existência de criança desde os tempos remotos, mas sem a existência da infância, define que essa categoria foi construída gradativamente.

Nesse sentido, o presente artigo refere-se a um recorte da pesquisa intitulada "A Ludicidade como eixo estruturador das culturas da infância, dando voz a criança", que visa à construção histórica da infância e como os pequenos são tratados dentro do contexto escolar.

A Ludicidade, segundo Sarmento (2003) é a atuação mais significativa das crianças e necessita estar presente em todos os contextos vivenciados por elas. Ao dizermos "dar voz a criança" não nos referimos apenas a palavras, mas em todas as formas de expressão de seus sentimentos.

As crianças falam por gestos, por olhares, por ações. Em cada movimento elas podem estar querendo dizer algo, e são nesses momentos que os nossos olhares precisam estar atentos para entender a mensagem que nos está sendo passada.

Os objetivos dessa pesquisa referem-se a analise de como a ludicidade ocorre no interior de uma instituição de Educação Infantil, compreender como esse eixo é trabalhado pelas professoras e observar a relação das crianças com a brincadeira. Além destes, procura-se promover espaço para que os pequenos possam se manifestar de maneira criativa.

\section{METODOLOGIA}

O presente estudo é realizado pelo grupo de pesquisa CEPELIJ ${ }^{2}$ em parceria com uma escola

\footnotetext{
1 "História Social das Crianças e da família" 1981, com iconografias francesas de um contexto financeiramente favorecido.

${ }^{2}$ CEPELIJ: Centro de estudo e pesquisa em educação, ludicidade, infância e juventude.
}

periférica de Presidente Prudente. Conta com a parceria de uma escola de Educação Infantil do mesmo munícipio, onde os bolsistas trabalham com 54 crianças e duas professoras. É financiada pela agência de fomento Pibic/Cnpq. Trata-se de uma pesquisa qualitativa do Tipo - Etnográfica.

A etnografia compreende a entrada do pesquisador no mundo do pesquisado, no caso em questão, assumimos algumas ferramentas da etnografia, mas passamos um tempo reduzido no contexto que estudamos.

As observações na escola acontecem uma vez na semana. Todas as análises são registadas no diário de campo e em vídeos e fotografias. Com as professoras são realizadas entrevistas, diálogos e observações das atividades e com as crianças, além das observações, trabalhamos com o registro de suas concepções em desenhos, que ocorrem com o auxilio das bolsistas de um projeto de extensão que atuam na mesma instituição escolar. Afim de não interpretar o que elas estão falando, mas apenas considerar suas informações, as bolsistas vão perguntando e anotando o que os pequenos estão desenhando. Os nomes das crianças citados no decorrer do artigo são fictícios, sendo eles representados por personagens de desenhos animados e super - heróis, escolhidos pelas próprias crianças.

Por ser uma pesquisa realizada com crianças, se fez necessário a sua aprovação pelo comitê de ética, correspondendo ao seguinte número: 13424213800005402.

\section{RESULTADOS}

É imprescindível mencionar que a pesquisa em questão é realizada juntamente com as crianças e não sobre crianças. Elas são protagonistas das vivências e auxiliam na elaboração das atividades, visto que as bolsistas aos términos das observações, perguntam aos pequenos o que querem fazer na próxima aula. Quando se estabelece um trabalho com crianças, elas precisam permitir que o adulto entre em seu espaço. Elas não gostam de um adulto com atitudes infantis, mas de alguém que seja realmente adulto e consiga entender o que esta acontecendo em seu mundo, o que Corsaro (2009) concebe como um adulto atípico.

No momento que o adulto começa a entender a criança a partir da perspectiva de vida tida por ela, ele estreita uma relação de confiança com os pequenos que abre espaço para a descoberta do seu mundo. Uma das salas estudadas vem sendo acompanhada pelo projeto 
de extensão desde o maternal. Diante de relatos das bolsistas e das observações com essas crianças, elas sempre foram submetidas a atividades lúdicas e imaginárias. A outra turma, por sua vez, passou a ter esse aporte desde o ano passado (2015). A diferença entre as duas salas é inegável. Os alunos que recebem esse tratamento diferenciado desde os seus 24 meses tem uma resposta aos sentidos das culturas infantis muito mais ampla do que os que estão adentrando agora nessa realidade. Não que os que iniciaram o ano passado não tenham a mesma essência de infância, mas a maneira que esses elementos se afloram são distintas e menores.

Observamos que em ambas as salas, a brincadeira foi à chave para manter as crianças como protagonistas. Toda brincadeira que era apresentada continha elementos imaginários. As bolsistas trabalhavam com contação de histórias, caças, brincadeiras cantadas e atividades de correria, sempre enfatizando o mundo encantado de personagens infantis. $O$ intuito era levar atividades que impulsionassem vivências fora de seu contexto.

Um exemplo disso foi à manhã na praia. Por se tratar de uma cidade no interior paulista distante do litoral, a maioria das crianças nunca viu o mar a não ser por vídeos e fotografias.

A escola possui um espaço com areia, onde as crianças brincam às vezes. As bolsistas levaram um pedaço de TNT azul e colocaram ao lado desse espaço, simbolizando o mar. E na areia espalharam brinquedos como baldes, pás, rastelos, carriolas e outras coisas semelhantes.

Sentamos no canto da quadra e observamos como eles se portavam. As crianças chegaram correndo e foram direto nos brinquedos, de repente o Lanterna Verde levantou e disse: Vou nadar de verdade, - e sem pensar deitou-se no TNT o transformando no mais profundo oceano. Na beira da praia o Thor estava enchendo os baldes e fazendo bolos, quando a Bela Adormecida chegou e perguntou:

- Por que vocês conseguem fazer bolos tão rápido?

Batman).

- Porque a gente sabe! (Respondeu o

- Ah e eu posso fazer também?

Nesse instante o Lanterna Verde saiu do mar, sentou-se com as crianças e disse: Sim, ajuda a encher os baldes. (DIÁRIO DE CAMPO).

As crianças dessa turma específica tem uma capacidade interativa que nos impressiona. Não importa quais brincadeiras eram expostas e quais contextos estavam sendo vivenciados, elas sempre se uniam e colocavam na brincadeira um pouco do que cada um queria.

Em outra situação, elas estavam cavando a terra e falando que era um escorregador. Cinderela enquanto enchia um pote com areia nos dizia que estava fazendo um "pundio". (Doce de leite condensado conhecido como pudim).

Enquanto estávamos observando e fazendo nossas considerações, um aluno se aproximou com um pouco de areia e nos disse que era massa de bolo de milho. Ao perguntarmos seu nome ele respondeu: Homem Aranha.

Durante toda a pesquisa estamos usando o nome das crianças como personagens, porém, nesse momento, a criança realmente disse que se chamava Homem Aranha. No mesmo instante, um outro aluno apareceu dizendo que se chamava Flash, nos puxaram pelas mãos e nos levaram para mergulhar no mar.

Todas as crianças se aproximaram e disseram que dentro desse mar havia um jacaré muito feroz e faminto. À medida que íamos atravessando as águas marinhas, eles jogavam areia do outro lado do mar, a fim de nos proteger e matar o carnívoro. Em todas as vivências as crianças estiveram como protagonistas e a capacidade imaginativa delas aflorava a cada história

Em uma das observações, as atividades na escola precisavam ser finalizadas antes do horário normal, portanto, a aula foi submetida com as duas salas ao mesmo tempo. Por mais que a euforia tivesse tomado conta do local, todas as crianças participaram das brincadeiras e deram suas contribuições. E para a nossa surpresa, as professoras também.

Ah eu acho que vou brincar também professora. Afinal, hoje eu não vim de calça branca, então posso sentar no chão. (risos). "Venham crianças. Vamos todos brincar porque depois vocês vão querer saber de novo e eu não vou saber. Venha Kelly ${ }^{3}$, chame a sua sala". (DIÁRIO DE CAMPO, PROFESSORA ANITA, 01/06/2016).

\footnotetext{
${ }^{3}$ Kelly: Nome fictício dado a professora de uma das salas de Educação Infantil.
} 
Essa foi uma das observações mais significativas, pois realmente vimos à vontade das professoras em estarem ali. Pelo fato das salas estarem juntas, a intervenção durou dez minutos a mais do que costuma ser normalmente e as crianças não queriam parar de brincar.

"Professora, mas já acabou? Porque a gente só brincou de duas coisas? Não deu tempo de nada! A gente tem que brincar de novo". (DIÁRIO DE CAMPO, ELSA, 01/06/2016).

Mas só isso? A gente não vai brincar de pintinho comendo o milho ${ }^{4}$ ? (DIÁRIO DE CAMPO, CAPITÃO AMÉRICA, 01/06/2016).

Mencionaremos na discussão desse artigo, que o tempo da criança é diferente do adulto, para eles, por mais que as bolsistas tenham ficado cronologicamente a mais que o comum, a vivência estava tão prazerosa que não poderia se findar.

\section{DISCUSSÃO}

Como já mencionado no início desse estudo, as crianças na idade média não eram consideradas diferentes dos adultos, mas não se pode negar que os pequenos recebiam os cuidados básicos para a sobrevivência, havia alguém que os amparava. Quando se diz que nesse período não existia sentimento de infância, os autores estão mencionando que as crianças eram vistas sem o respeito de uma categoria social, não sendo reconhecidas como atores sociais.

[...] o sentimento de infância não existia - o que não quer dizer que as crianças fossem negligenciadas, abandonadas ou desprezadas. O sentimento de infância não significa o mesmo que afeição pelas crianças: corresponde à consciência da particularidade infantil, essa particularidade que distingue essencialmente a criança do adulto, mesmo jovem. Essa consciência não existia. (ARIÈS, 1981, p.156)

Compreendemos a partir disso que era obscuro o entendimento de que a infância é um período diferente de qualquer outro, que existem idades distintas durante a vida que devem ser respeitadas. As mudanças dessas situações começaram a serem observadas quando os

\footnotetext{
${ }^{4}$ Mamãe Galinha: Atividade realizada na primeira intervenção do ano de 2015 , onde a professora era a mamãe galinha e alimentava os pintinhos (as crianças) com milho.
}

pintores deram início às obras de crianças já falecidas, retratando também que guardavam lembranças daqueles que já se foram. A partir dessas novas concepções, outras teorias foram sendo exploradas e a maneira como as famílias sofriam as perdas das crianças mostrou o novo sentimento.

O que a Sociologia da Infância denota é que a criança é um sujeito ativo, particular e protagonista. Ela desmembra o pensamento de uma criança apartada da sociedade e nomeia a relação da criança com a sua realidade e suas ações de Reprodução Interpretativa. A Reprodução Interpretativa enfatiza a capacidade de a criança reinventar o seu contexto a partir do que denomina-se "rotinas culturais". Esse aparato cultural propicia aos pequenos a segurança de que pertencem a um grupo social e não encontram-se alienados em um mundo desconhecido. Além disso, dá ênfase na interpretação do que se vive e a reformulação do que será produzido. Segundo Corsaro (1992), tais rotinas auxiliam as crianças no que é inesperado e diferente, tornando-as atores sociais.

Segundo Prout (2010), a Sociologia da Infância encontra-se em fase de aprimoramento, visto que a mesma iniciou-se da Sociologia Moderna, considerando o que há de positivo nela e rejeitando os pareceres que abortam o posicionamento ativo da criança. No entanto, o próprio autor define como louvável uma Sociologia que enfatize as particularidades da criança, a considerando como sujeito e valorizando as Culturas da Infância.

As crianças produzem e possuem particularidades, mas essas são envolvidas no contexto em que o adulto que a educa se encontra. Diante disso, Sarmento (2003) nos apresenta quatro eixos que estruturam as culturas infantis: Interactvidade, Ludicidade, Fantasia do Real e Reiteração.

A Interactividade é a relação que a criança estabelece com seus pares; a Ludicidade é o que a criança tem de mais significativo, a sua maneira de entender o mundo, a Fantasia do Real é a capacidade imaginativa da criança e a Reiteração equivale ao tempo recursivo apresentado por elas.

Destes, a Ludicidade é o aporte principal de nossos estudos. Tomada como sinônimo de brincadeira, além de ser o momento de prazer e satisfação, constitui-se do que a criança faz de mais significativo. São nessas vivências que elas reinventam seus mundos. Impedir que uma 
criança brinque e explore a sua imaginação é não permitir que ela se desenvolva completamente.

As instituições educacionais estão sendo cada vez mais o local onde as crianças passam grande parte de seus dias, quando não passam o dia todo nessa realidade. Portanto precisamos subsidiar as vivências lúdicas e amparar as relações entre infância e brincadeira.

\section{CONCLUSÃO}

No decorrer de nossas observações percebemos que as professoras que antes não demonstravam tanto interesse pela Ludicidade, agora se mostram mais presentes nas vivências. Todo esse processo foi uma construção, analisada aula após aula. As crianças esperavam ansiosamente por esses momentos, e quando as bolsistas finalmente chegavam, não queriam as deixar partir. É importante denotar que a relação das professoras com os alunos se mantinha bem mais próxima quando elas estavam dispostas a participarem de suas vivências, isso se remete ao que mencionamos do adulto que consegue a permissão de entrar no mundo da criança.

A mente de uma criança é cercada por descobertas e inovações e dar voz a ela é permitir que a mesma exprima a sua visão de mundo. Nessa fase da vida, elas estão tentando descobrir o que é esse complexo de pessoas em que vivemos e qual a importância delas nele. $E$ a escola, por sua vez, tem o papel de auxiliar nessa descoberta, visto que as responsabilidades sobre as crianças não se resumem apenas a família, por mais que essa seja a primeira agência geracional responsável pelos cuidados básicos e educação, mas compete a toda a sociedade.

\section{REFERÊNCIAS}

ARIES, P. História social da criança e da família. 2. ed. Rio de Janeiro: Livros Técnicos e Científicos, 1981.

BARBOSA, M. C. S. Culturas escolares, culturas de infância e culturas familiares: as socializações e a escolarização no entretecer destas culturas.

Educação \& Sociedade, Campinas, v. 28, n. 100, (Esp.), p. 1059-1083, out. 2005.

CHAUI, M.Filosofia moderna. In: Primeira Filosofia: aspectos da Historia da Filosofia. 10. reimpr. São Paulo: Brasiliense, 1996.

CORDEIRO, S. S.; COELHO, M. G. P. Descortinando

o conceito de infância na história: do passado à contemporaneidade. jun. 2007. Disponível em: <http://www.faced.uf.br/colulhe06/anais/arquivo/
76SandroSilvaCordeiro_MariaPintoCoelho.pdf>. Acesso em: 28 nov. 2008.

CORSARO, W. A. Reprodução interpretativa em culturas de mesmo nível infantil. Social Psicologia, v.55, n. 2, p. 160-177, 1992.

CORSARO, W. Sociologia da infância. 2. ed. Porto Alegre: Artmed, 2011.

HOLANDA, A. B. Mini Dicionário da língua

portuguesa. São Paulo: Saraiva, 2010.

MÜLLER, F.; CARVALHO, A. M. A. Encontros e diálogos: notas introdutórias. In: MÜLLER, F.; CARVALHO, A. M. A. (Orgs.). Teoria e prática na pesquisa com crianças: diálogos com Willian Corsaro. São Paulo: Cortez, 2009.

O COMEÇO da vida. Direção de Estela Renner. Brasil: P\&B.Marina Faria Filmes, 2016.

PROUT, A. Reconsiderando a nova sociologia da infância.. Cadernos de Pesquisa, São Paulo, v. 40, n. 141, p.729-750, set. 2010. Disponível em: < https://doi.org/10.1590/S0100$15742010000300004>$.

QVERTRUP, J. A infância enquanto categoria estrutural. Educação e Pesquisa, São Paulo, v. 36, n. 2, p.631-643, maio 2010.

https://doi.org/10.1590/S1517-

97022010000200014

SARMENTO, M. J.. As culturas da infância nas encruzilhadas da $2^{\circ}$ modernidade. Instituto de Estudos da Criança, Universidade do

Minho, Portugal, 2003. , p.1-22

SARMENTO, M. J. Gerações e alteridade:

interrogações a partir da Sociologia da

Infância. Educação Social, Campinas, v. 26, n. 91, p.361-378, 2005. <https://doi.org/10.1590/S0101$73302005000200003>$

SIROTA, R. Emergência de uma sociologia da infância: evolução do objeto e do olhar. Cadernos de Pesquisa, São Paulo, . n. 112, p.7-31, mar. 2001. http://dx.doi.org/10.1590/S0100-

15742001000100001.

VEYNE,P. O Império Romano. In: ARIÈS \& DUBY. historia da vida privada. São Paulo: Cia das Letras, 1994.v..1.

Recebido para publicação em 19/08/2016

Revisado em 22/08/2016

Aceito em 29/08/2016 